\title{
O papel dos psicólogos em situações de emergências e desastres
}

\section{The role of psychologists in emergency and hazard situations}

\author{
Melina Carvalho Trindade* \\ Universidade Franciscana - UNIFRA, Santa Maria, Rio Grande do Sul, Brasil \\ Monise Gomes Serpa ** \\ Universidade Franciscana - UNIFRA, Santa Maria, Rio Grande do Sul, Brasil
}

\begin{abstract}
RESUMO
Os desastres podem resultar em danos pessoais, materiais, ambientais e humanos. Sob essa perspectiva, este trabalho visa discorrer sobre as possíveis intervenções do psicólogo e colaborações da Psicologia frente aos eventos de emergências e desastres. Para isso, é realizada uma pesquisa qualitativa, na qual é aplicada uma entrevista semiestruturada com dois psicólogos que atuam nessas situações. O estudo revela uma mudança do enfoque dos profissionais da Psicologia quanto ao tema, que passa do diagnóstico à prevenção das comunidades, propondo intervenções que priorizam a subjetividade das pessoas. Também é apontada a importância do assunto ser discutido e desenvolvido em políticas públicas e de modo interdisciplinar. Ressalta-se ainda que o papel do psicólogo nesse contexto é amplo, abrangendo os diversos campos da Psicologia.
\end{abstract}

Palavras-chave: Emergências e desastres, Atuação do psicólogo, Psicologia.

\begin{abstract}
Disasters can result in personal, material, environmental and human harm. From this perspective, this work aims to discuss about the possible psychological interventions and the Psychology collaboration facing emergency events and disasters. Therefore, a qualitative research is carried out, in which a semi-structured interview with two psychologists who work in these situations is applied. The study demonstrates a change in the Psychological professional approach regarding the theme, which goes from the diagnosis to the community prevention, proposing interventions that set people's subjectivity as a priority. It is also stressed the importance of the subject being discussed and developed in public policies and in an interdisciplinary way. Furthermore, it is emphasized that the psychologist role in this context is broad, covering the several Psychology fields.
\end{abstract}

Keywords: Emergency and hazard situations, Role of psychologists, Psychology. 


\section{I ntrodução}

Este artigo é resultado de um Trabalho de Conclusão do Curso de Psicologia do Centro Universitário Franciscano - UNIFRA, de Santa Maria, Rio Grande do Sul, e tem por finalidade discorrer sobre o papel do psicólogo em situações de emergências e desastres ${ }^{1}$ resultantes de fenômenos naturais e da ação do homem na natureza. Pretende ainda identificar as colaborações da Psicologia para 0 desenvolvimento dessa temática no Brasil, onde o estudo é recente e, embora não existam tsunamis ${ }^{2}$ ou terremotos significativos, há enchentes, deslizamentos e secas cada vez mais frequentes.

No entendimento da Defesa Civil brasileira, os desastres ${ }^{3}$ naturais, como o próprio nome indica, são ocasionados por fenômenos da natureza. Já os que derivam da ação humana são denominados mistos (LOPES et al, 2009). De acordo com Kuhnen (2009), quando os desastres têm causas não-naturais ficam nítidas as consequências da ação do homem. Contudo, desastres aparentemente naturais geralmente também são agravados pelas ações humanas, que podem vir a provocar ou a intensificar o evento.

A ação dos fenômenos naturais é intensificada frente ao resultado da urbanização crescente, pobreza e meio ambiente (MOURA e SILVA, 2008). Heredia (2006) menciona que caracterizar os desastres como naturais realça o evento, mascarando a violência humana direta e indireta que existe nesse processo, tais como, a marginalidade social e econômica, e a inconsequente exploração dos recursos da natureza. Castro (1997) destaca que a intensidade dos desastres depende muito mais do grau de vulnerabilidade das comunidades do que da magnitude dos eventos adversos. Como exemplo, o autor cita que terremotos com intensidade de 6.5 graus na escala Ritcher, em 2008, provocaram 5 óbitos na Califórnia, enquanto que no Cairo 20 mil e na Armênia 40 mil. Constata, em decorrência, que os desastres podem ser minimizados, enfatiza a importância de haver uma mudança cultural em relação ao senso de percepção de risco, abrindo, assim, possibilidades para o enfrentamento dessa situação por meio da prevenção.

Kuhnen (2009) afirma que a percepção é a captação, seleção e organização das informações ambientais, que permite a tomada de decisão para uma ação inteligente. Ela é aprendida e está carregada de afetos que vão inferir sobre os juízos que se faz acerca do ambiente, e nas intenções que visem a mudanças no meio. Dessa forma, a percepção do ambiente admite a interferência do indivíduo.

A prevenção de desastres constitui-se, a priori, em compreender os fatores que geram os fenômenos naturais, e a aumentar a capacidade de resistência da sociedade contra esses fenômenos. Desse modo, a prevenção dos desastres naturais faz com que a vulnerabilidade da 
população seja evitada e, através disso, que se obtenha uma vida saudável (KOBIYAMA et al., 2004).

Nas comunidades onde há familiaridade com os eventos de alta frequência, as pessoas apresentam uma tendência de respostas mais sistemáticas, e, consequentemente, menor vulnerabilidade social (MATTEDI, 2008). Sendo assim, o não saber o que fazer em situações de desastres aprofunda a crise, porque o medo e o pânico bloqueiam a reflexão (ROZEN, 2006).

O conceito de resiliência no tema de redução de desastres é novo e pouco definido. Entretanto, sabe-se que ele diz respeito ao aprendizado quanto aos riscos e à prevenção, e àquele que ocorre no momento do impacto, fomentando esclarecimentos das ideias quanto ao que deve ser feito para melhorar as fases de prevenção e reconstrução (BRASIL, 2010). Nesse sentido, Mattedi (2006) argumenta que apesar de os desastres representarem uma ameaça para as comunidades, também são uma oportunidade para a comunidade e para os indivíduos se conhecerem melhor.

A comunidade bem informada é capaz de agir prevenindo e minimizando a fase pós-evento, que é de reconstrução e/ou compensação dos prejuízos ocasionados por desastres naturais. Nessa fase, as perdas e custos são superiores à etapa do pré-evento, em que se pode prevenir ou mitigar os futuros desastres (KOBIYAMA et al, 2004). Desse modo, a resposta das pessoas perante o desastre está intimamente ligada às atividades que são realizadas durante a fase de prevenção (KUHNEN, 2009).

Câmara (2008) menciona que a partir do processo de empoderamento, ou seja, de fortalecimento da comunidade, por meio da participação ativa dos moradores, é possível fazer com que eles adquiram uma atitude crítica crescente voltada a analisar os problemas e a identificar possíveis soluções. Dessa forma, conforme a autora, podem haver mudanças interpessoais, organizacionais e comunitárias que, no caso da prevenção dos desastres, é fundamental.

A questão dos desastres envolve necessariamente a relação do homem com seu ambiente, e, em face disso, o tema se torna relevante para a Psicologia (FAVERO e DIESEL, 2008). O primeiro estudo que envolveu a compreensão das emoções das pessoas envolvidas em situações de desastres foi realizado por Edward Stierlin, nos Estados Unidos, em 1909. Por outro lado, somente em 1944, com o trabalho de Linderman, é que se deu início a um sistema organizado de pesquisa e intervenção envolvendo desastres e Psicologia. Nessa pesquisa foi feito um levantamento das reações psicológicas dos sobreviventes de um incêndio de uma boate, intervindo, assim, na área do pós-desastre (COÊLHO, 2006).

O comportamento das pessoas perante as situações de desastres é o resultado de como cada comunidade percebe e administra as suas 
ameaças de desestabilização, ou das estratégias de adaptação psicológicas (MATTEDI, 2008). Por este fato, para o autor, a contribuição da Psicologia para a construção de comunidades mais seguras dá-se inicialmente na caracterização dos fatores que as ameaçam.

As moradias que são suscetíveis às inundações, segundo Siena e Valencio (2006), colocam em risco a integridade física e emocional dos que lá residem. Conforme as autoras, quando a moradia é destruída ou danificada estruturalmente, as repercussões sobre a rotina da família são complexas, visto que as redes sociais de convivência dos familiares envolvidos são modificadas. Esse processo envolve a perda dos bens permanentes e de consumo da família, tais como, móveis, alimentos e vestuário, ou seja, envolve a perda do que é preciso para satisfazer as necessidades dentro e fora do lar. Além disso, o deslocamento dos moradores para outro lugar, quando há risco de perda da moradia, ou então, quando o colapso já ocorreu, faz com que surja a condição de desalojado ou de desabrigado ${ }^{4}$ (SIENA e VALENCIO, 2006).

Para Cordani (1995), os cientistas e profissionais de distintas especialidades terão que se adaptar e buscar formas de atuação nos problemas globais, como na questão dos desastres. Nesse sentido, Mattedi (2008) ressalta que o tema desastres é objeto de estudo internacional, inclusive da área da Psicologia, e que provavelmente o maior desafio esteja na inclusão dessa temática na formação e na atuação profissional.

Portanto, pode-se perceber que assim como as outras ciências, a Psicologia tem colaborado com o estudo de emergências e desastres, buscando compreender esses fenômenos e sua relação com o homem para poder reduzir seus danos ou até a ocorrência dos eventos. Desse modo, é possível desenvolver com os indivíduos e as comunidades vulneráveis novas formas de perceber e de enfrentar a situação.

\section{Método}

\subsection{Delineamento}

A pesquisa realizada foi de cunho qualitativo, porque lidou com interpretações das realidades sociais e permitiu maior profundidade acerca do fenômeno estudado (BAUER e GASKELL, 2002). Optou-se pelo tipo exploratório, que conforme Gil (2006), caracteriza pesquisas desenvolvidas com a finalidade de proporcionar uma visão geral e aproximativa sobre um determinado fato. Esse tipo de pesquisa também é realizado quando o tema escolhido é pouco explorado, 
visando a esclarecer uma problemática, ou formular hipóteses para estudos posteriores.

\subsection{Participantes}

Os participantes da pesquisa foram dois psicólogos, um do sexo feminino e outro do sexo masculino, que atuam em situações de emergências e desastres. Para analisar os dados obtidos através das entrevistas realizadas e para preservar a identidade dos participantes, eles foram denominados como participante A (sexo masculino) e participante B (sexo feminino).

\subsection{Instrumentos}

O instrumento utilizado foi uma entrevista semiestruturada, seguindo um roteiro pré-estabelecido, contendo questões sobre: a formação profissional dos participantes; eventual contribuição e envolvimento na área de emergências e desastres; possíveis campos de atuação do psicólogo nessas situações; estratégias teóricas e metodológicas que podem ser utilizadas nesses eventos; procura pelo psicólogo das pessoas que estão vulneráveis, ou que sofreram com os impactos dos desastres; e percepção dos profissionais das outras áreas em relação à demanda do trabalho do psicólogo nessas situações.

\subsection{Procedimentos}

Preliminarmente, o projeto de pesquisa foi encaminhado para uma banca de qualificação composta por dois professores da UNIFRA e, posteriormente, submetido à Comissão de Ética desta Instituição de Ensino Superior (IES). Foi feito um levantamento dos psicólogos brasileiros que apresentaram seus trabalhos no I Seminário Nacional de Psicologia das Emergências e Desastres, realizado em Brasília, em 2006. A partir disso, dois psicólogos foram convidados via e-mail e por telefone para participarem desta pesquisa. Mediante a confirmação de participação, foi agendado um encontro que ocorreu em um congresso científico de Psicologia, no qual os participantes estavam presentes. As entrevistas foram realizadas em dias diferentes e ambas ocorreram em uma sala do evento, durante 0 horário do almoço. Elas tiveram duração de 24 minutos, e de 35 minutos, respectivamente. Os participantes assinaram um Termo de Consentimento Livre e Esclarecido (TCLE), autorizando sua participação e utilização das respostas na posterior análise de dados. As entrevistas foram transcritas e mantidas fidedignamente conforme as falas dos entrevistados. A identidade dos participantes será mantida em sigilo. 


\subsection{Análise de dados}

Os dados foram examinados por meio do método da análise de conteúdo empregado por Deslandes, Gomes e Minayo (2007). Na análise, foram construídas as seguintes categorias: Psicologia das emergências e desastres: do diagnóstico à prevenção; Contribuições da Psicologia: a demanda a partir da subjetividade, e A práxis do psicólogo nas situações de emergências e desastres: uma perspectiva generalista e interdisciplinar.

\section{Resultados e discussão}

\subsection{Psicologia das emergências e desastres: do diagnóstico à prevenção}

A partir da análise dos relatos fornecidos pelos participantes da pesquisa é possível verificar que a área de atuação do psicólogo em situações de emergências e desastres é ainda muito recente no Brasil, e por isso, está em processo de desenvolvimento. Conforme os participantes, um dos interesses atual da Psicologia é enfrentar a perspectiva psiquiatrizante ${ }^{5}$ desse campo, em que são realizadas intervenções que priorizam o pós-desastre, ou seja, o diagnóstico, permeado por um conceito de doença e consequente medicalização no tratamento de traumas.

\footnotetext{
[...] O tema do sofrimento dessas populações estavam fortemente inscritos no hall da temática, do stress póstraumático, de perspectiva medicalizante, de perspectiva epidemiológica medicalizante, de perspectiva, inclusive, de, entenda, a perspectiva medicalizante com forte componente de incremento de fármacos, psicofármacos [...] (PARTICIPANTE A).
}

Segundo Ruiz (2006), alguns anos atrás se considerava que a ruptura que ocorre no cotidiano e no ciclo vital das pessoas diante de um desastre fosse traumática para todos que vivenciavam essas situações, tornando-os doentes psiquiátricos. De acordo com os participantes, o enfoque da Psicologia estava situado na abordagem clínica e diagnóstica, a qual era realizada pelos psicólogos para intervir nas situações de emergências e desastres:

[...] Existiam concepções que já estavam presentes nesse campo, por exemplo, que trabalhavam na perspectiva de terapias clínicas, elaboração de luto, com conceitos, às vezes, bastante restritos sobre o que faz um psicólogo, né, qual é a missão do psicólogo, muito voltado para um viés clínico, por exemplo [...]. (PARTICIPANTE A) 
[...] A maioria dos estudos voltados para os eventos de grandes desastres e grandes emergências era voltado para uma visão diagnóstica dos sobreviventes, tá entendendo? Esporadicamente era que você via algum relato, mas muito incipiente, de como as comunidades de alguma forma conseguiam lidar com tudo isso [...] (PARTICIPANTE B).

Até a metade do século passado, os estudos relacionados às emergências e desastres eram escassos. Mas com o advento da Segunda Guerra Mundial e mediante uma visão psiquiátrica característica da época, eles se voltam a entender as reações das pessoas diante da possibilidade de um ataque nuclear (COÉLHO, 2006). Para a autora, talvez por isso a ênfase da Psicologia no tema de desastres tenha sido de diagnóstico.

Entretanto, pode-se observar o rumo que o estudo da Psicologia das Emergências e Desastres tem tomado nos últimos anos:

[...] Então eu vejo assim, um avanço nesse sentido, de uma preocupação na formação desse tipo de trabalho voltado para metodologias mais participativas, vê as pessoas como sobreviventes, não vitimizá-las, né, que elas sabem o que querem, elas têm o poder de discernimento se for dada as opções (PARTICIPANTE B).

Antigamente, a recomendação da Defesa Civil brasileira para lidar com desastres era a de não conversar com as comunidades que estavam em risco para que não houvesse alarme e caos social (VALENCIO, 2009a). Entretanto, esta visão mudou e o que se sabe é que a comunidade quando consciente dos riscos que sofre em relação ao desastre, está mais bem preparada para evitar, minimizar os impactos e agir diante desses eventos. Conscientizar a comunidade é protegê-la, sendo que é a resposta da comunidade que vai determinar o grau de impacto gerado pelos desastres (KOBIYAMA et al., 2009).

De acordo com Krum e Bandeira (2008), nos últimos anos observa-se um número crescente de estudos relacionados a grupos e comunidades atingidas por desastres. Segundo Góis (2005), a comunidade significa existência, pois é onde há confirmação da identidade pessoal e social, e onde acontecem as interações entre pessoas, municípios e sociedade. Por este motivo, para o autor, a comunidade é considerada cada vez mais importante no desenvolvimento da sociedade e do indivíduo. Câmara (2008) complementa que a mudança é conseguida através da união das pessoas, que é resultante do sentimento de pertença à comunidade.

Tradicionalmente, a Psicologia, por ter um caráter clínico mais difundido e acentuado, se preocupou em realizar intervenções que contemplavam somente o pós-desastre. Contudo, com 0 desenvolvimento da Psicologia e da temática, percebe-se a 
necessidade de ampliar esse conceito e de construir ações que visem à participação da comunidade na prevenção dos desastres, visto que ela pode agir e amenizar os impactos negativos desses eventos.

\section{Contribuições da psicologia: a demanda a partir da subjetividade}

Conforme o participante $A$, a partir do momento que houve a inclusão da Psicologia no tema das emergências e desastres, a assistência humanitária foi introduzida como paradigma. Dessa forma, a Psicologia colaborou com o início de ações que relevam a subjetividade, inclusive no âmbito da Defesa Civil.

[...] O fato das pessoas estarem em situação de desconforto,
não, é, não, não te permite a entender que qualquer
minoração do desconforto já é uma ação em si mesmo,
válida em si mesmo. Tipo assim, qualquer coisa já tá muito
bom, perdeu tudo, então se eu te dou umas roupas usadas,
se eu te boto num canto lá numa escola, se eu amontôo as
pessoas, já tirei do tempo, já tão sequinhas, já tô dando uma
cesta básica, tá bom. Então, é um paradigma rebaixador da
cidadania. Então, obviamente, que a entrada da Psicologia no
debate é que vai introduzir o tema, inclusive, do debate da
Defesa Civil brasileira, é que vai introduzir o tema da
assistência humanitária como paradigma [...]
(PARTICIPANTE A).

A preparação e a forma pela qual a situação será dimensionada em uma ocasião de desastre, ou seja, o modo como será realizada a intervenção, produz efeitos importantes. Se inadequada, pode, inclusive, acumular os danos para as pessoas (COÊLHO, 2006). Segundo Valencio (2009b), as medidas utilizadas para reduzir as vulnerabilidades diante dos eventos climáticos não podem ter caráter reducionista. Siena e Valencio (2009) apontam que para que as políticas públicas da Defesa Civil sejam mais eficazes é necessário situar o tema das emergências na perspectiva de promover a cidadania.

A assistência social atrelada ao direito da cidadania deve ser enfatizada, pois releva a ideia do acesso ao que é garantido como direito de cidadão. O problema está quando tal assistência deixa de ser provisória, gerando dependência (DEMO, 2001). Quanto a essa situação, Heredia (2006) considera que a participação ativa da comunidade evita que a assistência prestada se transforme em assistencialismo.

Para a participante $B$, a intervenção, em um primeiro momento, visa a realizar o acolhimento. É através dele que vai ser possível identificar se alguém está com algum comprometimento. 
[...] Mas quando eu [...] vou pra algum tipo de intervenção, eu vou com o sentido de acolhimento, de entendimento do que está sendo vivenciado. E com o passar do tempo é que você vai conseguir identificar se algumas pessoas tão com algum comprometimento e pra isso que a gente escuta os fatores mediadores porque uma das questões de pesquisa é que nem sempre o evento causa o mesmo nível de comprometimento [...] (PARTICIPANTE B).

O propósito das intervenções é conter ansiedades, auxiliar na descarga emocional, provocar a significação do que está sendo vivenciado pelo indivíduo, favorecer condutas participativas e promover a solidariedade entre as pessoas que sofreram com os impactos dos desastres. Dessa forma, a representação do desastre é derivada do sentido que essa situação tem para o sujeito que, por sua vez, é formada a partir das suas experiências particulares e coletivas. Sendo assim, na situação de desastre a magnitude do evento não é importante, mas sim o sentido que as pessoas atribuem para essas situações. Esse é o fator determinante para as diferentes reações das pessoas (HEREDIA, 2006).

Também é realçado pelos participantes da pesquisa que esta prática do psicólogo deve estar inserida em políticas públicas, como pode ser observado nos relatos a seguir:

[...] outra perspectiva que o Conselho Federal de Psicologia apontou, que eu acho que continua válida, que os esforços preferenciais para este, esta temática devem-se desenvolver no campo institucionalizado da política pública de Defesa Civil brasileira. [...] e que a atenção à saúde mental, em um capítulo específico do tema global da assistência humanitária e da abordagem das emergências e desastres, seja oferecido por pessoal do Sistema Único de Saúde, com preparo técnico, adequado para abordar esta temática, dentro das suas especificidades[...] (PARTICIPANTE A).

[...] Então eu creio que se você inserir o psicólogo como política pública, né, pra trabalhar, pra fazer as coisas, é, se você insere o psicólogo como parte de uma política pública de trabalho e tudo mais, você vai ter mais condições de que em acontecendo algum evento, aquela comunidade já conhece a pessoa. Porque uma coisa é [...] chegar de cara a cara em determinado canto, outra coisa é [...] fazer parte do trabalho desenvolvido naquela comunidade e eu permaneço fazendo isso. E o psicólogo tem, se ele faz parte de uma política pública, ele tem, é, contribuições para dar em todas as fases (PARTICIPANTE B).

Na concepção de Dimenstein (2001), o compromisso profissional do psicólogo na saúde coletiva está além de ser uma questão burocrática, envolvendo, a priori, ações e reflexões que propiciam a cidadania ativa, a sociabilidade e novas subjetividades. Paiva e 
Yamamoto (2010) argumentam que como os psicólogos são profissionais que se preocupam com o bem-estar, eles devem se ocupar das questões sociais. E que só há compromisso social da Psicologia se esta estiver ligada a um plano de mudança, buscando as causas do problema e medidas para solucioná-las, a partir de uma ação que vise à emancipação do sujeito.

Mattedi (2008) pontua que a Psicologia pode aplicar seu conhecimento de desastres no Programa de Saúde da Família. Favero e Diesel (2008) sublinham que o incentivo para os estudos de Psicologia das emergências e desastres no Brasil farão com que haja desenvolvimento no tema e que sejam oferecidos subsídios para políticas quanto à prevenção e intervenção em desastres.

Através da participação da Psicologia no tema das emergências e desastres, é possível construir formas de abordagens que priorizem a subjetividade das pessoas, baseadas no que o indivíduo estiver vivenciando no momento e no sofrimento psíquico em que se encontre. Com a inserção do psicólogo que atua nessa temática em políticas públicas, podem ser desenvolvidas ações favoráveis à comunidade, além de propiciar maior conhecimento e entendimento das pessoas acerca da prática do profissional de Psicologia nessas situações e melhor capacitar o psicólogo.

\section{A práxis do psicólogo nas situações de emergências e desastres: uma perspectiva generalista e interdisciplinar}

Nos discursos dos participantes identifica-se que a intervenção do psicólogo nas situações de emergências e desastres pode ocorrer nas três etapas do evento, ou seja, no pré-impacto, no impacto e no pósimpacto.

[...] O psicólogo que cuida disso tem que ser alguém que cuide da prevenção, da preparação, da resposta, da reconstrução[...] (PARTICIPANTE A).

[...] O psicólogo, ele pode atuar em todas as etapas. Desde a prevenção, trabalhando como as comunidades se veem. [...] Durante o momento de como construir os abrigos, como cuidar dessas pessoas lá; e na fase da reconstrução pra que as iniciativas de reconstrução sejam sempre voltadas pra um desenvolvimento sustentável da comunidade. E que essas estratégias não venham a fragmentar exatamente essa possibilidade da comunidade se reconstituir (PARTICIPANTE B).

Para Kobiyama et al (2004), na etapa pré-evento as ações são voltadas para prevenir ou mitigar os futuros danos. Durante o evento é possível realizar ações emergenciais; e a reconstrução das comunidades é realizada na etapa pós-evento. Nesse sentido, Molina 
(2006) colabora com a ideia que há uma quarta etapa de desastre que consiste em elaborar planos de ação diante das próximas emergências.

Contudo, é enfatizada a importância do trabalho ser realizado no préimpacto, ou seja, na preparação das comunidades. Para a participante $\mathrm{B}, \mathrm{a}$ prática do psicólogo deve estar voltada, principalmente, para a prevenção e promoção da saúde, como pode ser observado na fala a seguir:

[...] Eu vejo muito essa prática na área de Emergências e Desastres como uma prática voltada para o cuidado da saúde de forma ampliada. [...] A visão que se tem do psicólogo é que só tem espaço pra ele quando alguém está doente, e muito doente. Então, não há essa perspectiva do psicólogo trabalhando com promoção e prevenção (PARTICIPANTE B).

Conforme Ocampo (2006), o trabalho de prevenção e atenção primária em saúde mental para a comunidade vulnerável a sofrer desastres naturais é de suma importância. Portanto, é necessário que existam equipes de suporte nessas comunidades, compostas por grupos de profissionais que trabalham com o conceito de prevenção e promoção da saúde mental. $O$ autor alega ainda que as equipes de saúde mental podem simular situações de desastres para que, caso eles venham a ocorrer, a comunidade esteja preparada a se organizar, respondendo de modo benéfico à situação.

$\mathrm{Na}$ etapa pré-evento é muito importante trabalhar com a comunidade conceitos sobre o que é risco e a partir disso construir intervenções (COÊLHO, 2006). Os riscos fazem parte do aspecto da percepção qualitativa do ambiente e influenciam as pessoas a se darem conta de suas existências e a serem conscientes de sua vulnerabilidade, o que determinará a noção de cuidado (KUHNEN, 2009).

De acordo com o participante $A$, os profissionais de outras áreas, como os da Defesa Civil, percebem a importância do envolvimento do psicólogo em situações de emergências e desastres. Entretanto, para a participante $B$, as práticas do psicólogo ainda estão muito atreladas ao atendimento clínico, o que dificulta o entendimento dos outros profissionais acerca do fazer da Psicologia nesta área.

[...] Os profissionais da Defesa Civil, é, nutria uma grande expectativa, às vezes, até uma expectativa inadequada, indevida, fora de medida, meio mágica acerca do que fariam os psicólogos. Mas uma grande expectativa, porque eles percebem claramente que há algo da dimensão da subjetividade [...] eles não estão, não se sentem preparados pra lidar com essa dimensão da subjetividade que está em jogo nessas circunstâncias (PARTICIPANTE A).

[...] Quando eu falo na área que eu trabalho, não precisa nem tá acontecendo, eles dizem assim: "mas o quê o 
psicólogo vai fazer lá?". Por quê? Porque eles têm aquela visão do psicólogo, ainda, muito, aquela forma de consultório de atendimento. [...] Eles não entendem uma proposta de trabalho com as pessoas que estão aguardando alimentação, com as pessoas que estão aguardando cobertores, quando alguém precisa de alguém para acompanhar na hora de reconhecer um familiar. Tá entendendo? Então, são práticas que não estão ainda institucionalizadas (PARTICIPANTE B).

Os desastres causam muitos danos imateriais, ou seja, de valor simbólico e emocional para as pessoas. Por isso, recomenda-se o acompanhamento psicológico para aqueles que sofrem com stress acentuado diante da ruptura de suas rotinas pessoais, familiares, comunitárias, profissionais, entre outros (GERALDI, 2009). O acompanhamento psicológico da equipe de trabalho que intervém no desastre também é importante, visto que ela lida com situações extremas e imprevistas, que envolvem risco pessoal e responsabilidade com a integridade física e psicológica das pessoas (SILVA, 2009).

Percebe-se que a atuação nesse campo de trabalho com emergência e desastres é uma área também de intervenção psicossocial. Conforme Paiva e Yamamoto (2008) nos últimos anos a Psicologia tem mudado, construindo novas formas de saberes e compondo novas práticas. Segundo os autores, é necessário estabelecer uma Psicologia mais social, que conheça seu contexto de atuação e que colabore para a emancipação do sujeito.

Em relação ao perfil do profissional de Psicologia que irá trabalhar com as questões de emergências e desastres, o participante $A$ menciona que ele deve ter uma visão multifatorial da temática, com base na interdisciplinaridade.

[...] Você vai solicitar que o sujeito que vem pra isso, ele tenha uma visão sistêmica, complexa, né, da temática, de forma com que ele possa se inserir num dos esforços de outros setores da sociedade que estão envolvidos com isso. [...] O sujeito tem que ser um generalista no assunto de Emergência e Desastre, ele tem que ser um generalista, ele não pode ser um especializado dentro da especificidade [...] (PARTICIPANTE A).

O tema das emergências e desastres é complexo e interdisciplinar (OLIVEIRA, 2006). Dessa forma, o manejo dos desastres não pode estar vinculado somente a uma pessoa, sendo assim, deve fazer parte do conhecimento de uma equipe que esteja preparada para atuar nessas situações, com a qual o psicólogo também compõe (OCAMPO, 2006). Segundo Gómez (2006), o treinamento interdisciplinar constitui a capacitação do profissional da saúde mental que irá intervir em situações de desastres. 
A participante B cita que neste tema os saberes de todos os campos da Psicologia são necessários para o entendimento da situação e para a realização de intervenções.

\begin{abstract}
Porque vejas, você vai ter conhecimento da área de comunitária, da área de desenvolvimento humano, dependendo de onde você irá trabalhar, da área de organizacional, da área de psicologia social, pra entender grupo, movimentos, então todas as áreas da psicologia, da área clínica porque você também vai ter que ter um entendimento do que acontece, do que é [...] (PARTICIPANTE B).
\end{abstract}

Bindé (2006) cita que um dos desafios para construir um programa voltado à investigação em Psicologia dos desastres é circular entre as diversas áreas da Psicologia. Assim, deve-se assegurar que 0 psicólogo utilize os conhecimentos de diferentes campos para dar suporte às pessoas e aos profissionais envolvidos nos desastres para fortalecer o funcionamento da comunidade.

O psicólogo pode, portanto, atuar nas três etapas de formação dos desastres. Contudo, quando o trabalho é realizado na etapa de prevenção é possível evitar ou reduzir os impactos negativos do desastre. Tendo em vista que a intervenção nesse campo de trabalho é interdisciplinar, o psicólogo que participa da intervenção deve possuir habilidades para trabalhar em equipe e também saber que todas as áreas da Psicologia, assim como de outras disciplinas, serão necessárias para a efetivação de seu agir.

\title{
6 Considerações finais
}

Esta pesquisa possibilitou um maior entendimento acerca do papel do psicólogo em situações de emergências e desastres. Os resultados mostraram que a abordagem utilizada até há pouco tempo pelos psicólogos enfatizava somente a intervenção no pós-desastre, principalmente nos traumas oriundos da situação. Contudo, recentemente, houve uma crescente preocupação em realizar intervenções na preparação das comunidades para prevenir ou reduzir os impactos negativos desses eventos.

Ficou evidenciado que o psicólogo pode atuar nas três etapas de formação do desastre, ou seja, nas etapas pré, trans e pós-desastre. Na prevenção de desastres, a percepção de risco vai ser primordial para que o indivíduo e a sua comunidade compreendam a situação em que se encontram, e que a partir dessa constatação possam refletir na solução do problema. O psicólogo pode auxiliar no processo, assim como na formulação de propostas que visem à melhora da comunidade. Também é ressaltada a ideia de que quando 
o psicólogo atuar no pós-desastre, ele tenha uma visão ampliada da situação para lidar com sua complexidade, não se limitando apenas ao diagnóstico.

Foi apontado que a Psicologia colaborou para que as intervenções realizadas em situações de emergências e desastres priorizassem a subjetividade das pessoas. A partir disso, dá-se início a uma nova maneira de atuar nos desastres, que além de se preocupar com o bem estar físico das pessoas, dá importância ao seu bem estar psíquico, uma vez que também é o que determinará a sua reação frente aos eventos.

Entretanto, quando solicitado, o psicólogo geralmente é vinculado somente às práticas clínicas. Isso faz com que alguns profissionais ainda tenham dificuldade em reconhecer o trabalho deste profissional quando não realizado em consultório e com diferentes abordagens.

Outro aspecto mencionado foi o trabalho interdisciplinar, visto que o psicólogo é um dos profissionais da equipe que intervém em desastres. Também foi salientado que os saberes de todos os campos da Psicologia são necessários tanto para o entendimento da temática, quanto para a atuação do profissional. E foi sugerido que ocorra a inserção dessa prática do psicólogo em políticas públicas.

Tendo em vista que a atuação do psicólogo em situações de emergências e desastres é recente no Brasil, ainda não há um número significativo de trabalhos publicados e nem de profissionais atuantes nesse meio. No entanto, os dois participantes selecionados para a pesquisa é uma amostra significativa pelo engajamento tanto na atuação como nas discussões do tema. Da mesma forma, as conclusões demonstram um caminho novo pelo qual o psicólogo está percorrendo no que se refere às emergências e desastres.

Com base nessas constatações, sugere-se o aprofundamento dos estudos dessa temática no âmbito da Psicologia, devendo ser realizados encontros, seminários (inclusive com a participação da Defesa Civil), haver campo de estágio e incluir o tema na formação do psicólogo nas Universidades. Para elaborar estudos posteriores, a indicação é que esses sejam em relação ao perfil do psicólogo e à importância dessa temática fazer parte de políticas públicas. Bem como, trabalhos que abordem o que é necessário ser realizado na hora do impacto, e sobre propostas para reconstrução.

\section{Referências}

BAUER, M. W.; GASKELL, G. Pesquisa qualitativa com texto, imagem e som: um manual prático. Traduzido por Pedrinho A. Guareschi. Petrópolis: Vozes, 2002.

BINDÉ, P. Perspectivas de investigação em Psicologia das emergências e dos desastres na América Latina. In: I SEMINÁRIO 
NACIONAL DE PSICOLOGIA DAS EMERGÊNCIAS E DOS DESASTRES: CONTRIBUIÇÕES PARA A CONSTRUÇÃO DE COMUNIDADES MAIS SEGURAS, 2006, Brasília. Anais... Brasília: Finatec/UNB, 2006. p. 103-108.

BRASIL. Ministério da Integração Nacional. Secretaria Nacional de Defesa Civil. Universidade Federal de Santa Catarina. Centro Universitário de Estudos e Pesquisas sobre Desastres. Gestão de risco e de desastres: contribuições da psicologia. Curso à distância. Florianópolis: CEDEP, 2010.

BRYANT, E. Tsunami: the underrated hazard. 2. ed. Chichester: Praxis, 2008.

CÂMARA, S. G. Compromisso, participação, poder e fortalecimento comunitário: a procura de um lugar no mundo. In: DIMENSTEIN, M. (Org.). Psicologia social comunitária: aportes teóricos e metodológicos. Natal: EDUFRN, 2008, p. 43-58.

CASTRO, A. L. C. de. Segurança Global da População. Ministério da Integração Nacional. Secretaria Nacional de Defesa Civil. SEDEC, Brasília, set, $1997 . \quad$ Disponível em: <http://www.crid.or.cr/digitalizacion/pdf/por/doc10456/doc10456a. pdf>. Acesso em: 10 maio 2010.

COÊLHO, A. L. Psicologia das emergências e dos desastres: uma área em construção. História e desenvolvimento. In: I SEMINÁRIO NACIONAL DE PSICOLOGIA DAS EMERGÊNCIAS E DOS DESASTRES: CONTRIBUIÇÕES PARA A CONSTRUÇÃO DE COMUNIDADES MAIS SEGURAS, 2006, Brasília. Anais... Brasília: Finatec/UNB, 2006. p. 62-67.

CORDANI, U. G. As ciências da terra e a mundialização das sociedades. Estudos avançados, São Paulo, v. 9. n. 25, set./dez. 1995. Disponível em: <http://www.scielo.br/scielo. php?pid=S0103$40141995000300003 \&$ script=sci_arttext\&tlng=en>. Acesso em: 01 maio 2010.

DEMO, P. Brincando de solidariedade: política social de primeiradama. In: SILVA, M. O. S. (Coord.). Comunidade solidária: o nãoenfrentamento da pobreza no Brasil. São Paulo: Cortez, 2001, p. 4369.

DESLANDES, S. F.; GOMES, R.; MINAYO, C. S. (Orgs.). Pesquisa social: teoria, método e criatividade. Petrópolis: Vozes, 2007.

DIMENSTEIN, M. O psicólogo e o compromisso social no contexto da saúde coletiva. Psicologia em Estudo, Maringá, v. 6, n. 2, jul./dez. $2001 . \quad$ Disponível em: <http://www.scielo.br/pdf/pe/v6n2/v6n2a08. pdf>. Acesso em: 27 out. 2010.

FAVERO, E.; DIESEL, V. A seca enquanto um hazard e um desastre: uma revisão teórica. Alatheia, Canoas, n. 27, jun. 2008. Disponível 
em: <http: //scielo. bvs-psi.org. br/scielo. php?pid=S1413-

$03942008000100015 \&$ script=sci_arttext>. Acesso em: 12 maio 2010.

FILHO, J. F. S. A Medicina, a Psiquiatria e a doença mental. In:

Tundis, S. A., COSTA N. R. (Orgs.). Cidadania e loucura: políticas em saúde mental no Brasil. 7. ed. Petrópolis: Vozes, 2001. p. 75-102. GERALDI, D. Pessoas com deficiência visual: do estigma às limitações da vida cotidiana em circunstâncias de riscos e de desastres relacionados às chuvas. In: VALENCIO, N.; SIENA, M.; MARCHEZINI, V.; GONÇALVES, J. C. (Orgs.). Sociologia dos desastres: Construção, interfaces e perspectivas no Brasil. São Carlos: NEPED/UFSCAR, 2009. p. 107-118.

GIL, A. C. Métodos e técnicas de pesquisa social. São Paulo: Atlas, 2006.

GÓIS, C. W. L. Psicologia comunitária: atividade e consciência. Fortaleza: Publicações Instituto Paulo Freire de Estudos Psicossociais, 2005.

GÓMEZ, C. Saúde mental na gestão dos desastres: intervenção no cotidiano e nos eventos. In: I SEMINÁRIO NACIONAL DE PSICOLOGIA DAS EMERGÊNCIAS E DOS DESASTRES: CONTRIBUIÇÕES PARA A CONSTRUÇÃO DE COMUNIDADES MAIS SEGURAS, 2006, Brasília. Anais... Brasília: Finatec/UNB, 2006. p. 72-26.

HEREDIA, A. M. Psicologia e emergências sociais: intervenções nos cotidianos e eventos. In: I SEMINÁRIO NACIONAL DE PSICOLOGIA DAS EMERGÊNCIAS E DOS DESASTRES: CONTRIBUIÇÕES PARA A CONSTRUÇÃO DE COMUNIDADES MAIS SEGURAS, 2006, Brasília. Anais... Brasília: Finatec/UNB, 2006. p. 68-71.

KOBIYAMA, M.; CHECCHIA, T.; SILVA, R. V.; SCHRÖDER, P. H.; GRANDO, A.; REGINATTO, G. M. P. Papel da comunidade e da universidade no gerenciamento de desastres naturais. In: SIMPÓSIO BRASILEIRO DE DESASTRES NATURAIS, 2004, Florianópolis. Anais... Florianópolis: GEDN/UFSC, 2004. p. 834-846. (CD-ROM) Disponível em: <http://www.cfh.ufsc. br/ gedn/sibraden/cd/EIXO\%205_OK/565. pdf $>$. Acesso em: 06 maio 2010.

KOBIYAMA, M.; MOTA, A. A.; GIGLIO, J. N.; MICHEL, G. P.; GOERL, R. F.; CORSEUIL, C. W. Aprender hidrologia para prevenção de desastres naturais. In: $X$ CONGRESO IBEROAMERICANO DE EXTENSIÓN UNIVERSITARIA, 2009, Montevidéu. Anais... Montevidéu: Universidad de La República, 2009. (CD-ROM) Disponível em:

<http://www.labhidro.ufsc.br/Projetos/ARTI_2009/aprender\%20hidro logia\% 20para\% 20prevencao\% 20de\% 20desästres\% 20naturais. pdf $>$.

Acesso em: 06 maio 2010.

KRUM, F. M. B.; BANDEIRA, D. R. Enfrentamento de desastres naturais: o uso de um coping coletivo. Paidéia, Ribeirão Preto, v. 18, n. 39 , 2008. Disponível em: 
<http://www.scielo.br/scielo. php?pid=S0103863X2008000100008\&s cript=sci_abstract\&tlng=pt>. Acesso em: 06 de maio 2010.

KUHNEN, A. Meio ambiente e vulnerabilidade: a percepção ambiental de risco e o comportamento humano. Geografia, Londrina, v. 18, n. 2, 2009.2 Disponível em: <http://www.uel.br/revistas/uel/index.php/geografia/article/viewArti cle/3287>. Acesso em: 03 maio 2010.

LOPES, D. C.; BARROS, F. A. C.; FILHO, M. A. B.; SILVA, M. V. O. Construindo comunidades mais seguras: preparando para a ação cidadã em defesa civil. Florianópolis: UFSC/CEPED; Brasília: Secretaria Nacional de Defesa Civil, 2009.

MATTEDI, M. A. A questão da segurança na sociedade da incerteza. In: I SEMINÁRIO NACIONAL DE PSICOLOGIA DAS EMERGÊNCIAS E DOS DESASTRES: CONTRIBUIÇÕES PARA A CONSTRUÇÃO DE COMUNIDADES MAIS SEGURAS, 2006, Brasília. Anais... Brasília: Finatec/UNB, 2006. p. 88-93.

A abordagem psicológica da problemática dos desastres: um desafio cognitivo e profissional para a psicologia. Psicologia: Ciência e Profissão, Brasília, v. 28, n. 1, p. 162-173, 2008. Disponível em: <http://scielo.bvspsi.org.br/scielo. php?script=sci_arttext\&pid=S1414-

98932008000100012 >. Acesso em: 03 maio 2010.

MOLINA, R. Psicologia das emergências e dos desastres: uma área em construção. História e desenvolvimento a partir da perspectiva chilena. In: I SEMINÁRIO NACIONAL DE PSICOLOGIA DAS EMERGÊNCIAS E DOS DESASTRES: CONTRIBUIÇÕES PARA A CONSTRUÇÃO DE COMUNIDADES MAIS SEGURAS, 2006, Brasília. Anais... Brasília: Finatec/UNB, 2006. p. 54-61.

MOURA, R.; SILVA, L. A. A. Desastres naturais ou negligência humana? Revista Geografar, Curitiba, v. 3, n. 1, p. 58-72, jan./jun. 2008. Disponível em: <http://ojs.c3sl.ufpr.br/ojs2/index.php/geografar/article/view/ 12910 19191>. Acesso em: 01 maio 2010.

OCAMPO, H. T. Conferência: Sistemas de atenção às vítimas de situações de emergências e desastres: contribuições possíveis da Psicologia. In: I SEMINÁRIO NACIONAL DE PSICOLOGIA DAS EMERGÊNCIAS E DOS DESASTRES: CONTRIBUIÇÕES PARA A CONSTRUÇÃO DE COMUNIDADES MAIS SEGURAS, 2006, Brasília. Anais... Brasília: Finatec/UNB, 2006. p. 17-24.

OLIVEIRA, M. V. Perspectivas de investigação em Psicologia das emergências e dos desastres na América Latina. In: I SEMINÁRIO NACIONAL DE PSICOLOGIA DAS EMERGÊNCIAS E DOS DESASTRES: CONTRIBUIÇÕES PARA A CONSTRUÇÃO DE COMUNIDADES MAIS SEGURAS, 2006, Brasília. Anais... Brasília: Finatec/UNB, 2006. p. $109-113$. 
PAIVA, I. L.; YAMAMOTO, O. H. Os novos Quixotes da Psicologia e a prática social no "terceiro setor". Psicologia Política, São Paulo, v. 8, n. 16, p. 231-250, jul./dez. 2010.

Formação e prática comunitária do psicólogo no âmbito do "terceiro setor". Estudos de Psicologia, Campinas, v. 15, n. 2, p. 153-160, maio/ago. 2010.

ROZEN, S. C. As construções teóricas e práticas sobre os conceitos de emergência e desastres. In: I SEMI NÁRIO NACIONAL DE PSICOLOGIA DAS EMERGÊNCIAS E DOS DESASTRES: CONTRIBUIÇÕES PARA A CONSTRUÇÃO DE COMUNIDADES MAIS SEGURAS, 2006, Brasília. Anais... Brasília: Finatec/UNB, 2006. p. 39-44.

RUIZ, A. L. As construções teóricas e técnicas em torno dos conceitos de emergências e desastres. In: I SEMINÁRIO NACIONAL DE PSICOLOGIA DAS EMERGÊNCIAS E DOS DESASTRES: CONTRIBUIÇÕES PARA A CONSTRUÇÃO DE COMUNIDADES MAIS SEGURAS, 2006, Brasília. Anais... Brasília: Finatec/UNB, 2006. p. 31-39.

SIENA, M.; VALENCIO, N. F. L. S. Moradias Afetadas pelas Chuvas: dimensões objetivas e subjetivas dos danos pelo recorte de gênero. In: III ENCONTRO DA ANPPAS, 2006, Brasília, Anais... Brasília: ANPASS, 2006. Disponível em: <http://www.teia.fe.usp.br/biblioteca_virtual/Siena\%20e\%20Valenci o- $\%$ 20ANPPAS $\%$ 20-2006-

$\% 20$ Vulnerabilidade $\% 20 \mathrm{e} \% 20 \mathrm{GENERO} . \mathrm{pdf}>$. Acesso em: 05 maio 2010.

Gênero e desastres: uma perspectiva brasileira sobre o tema. In: VALENCIO, N.; SIENA, M.; MARCHEZINI, V.; GONÇALVES, J. C. (Orgs.). Sociologia dos desastres: construção, interfaces e perspectivas no Brasil. São Carlos: NEPED/UFSCAR, 2009, p. 58-66. SILVA, S. F. L. Cooperação e visão sistêmica em equipes de trabalho: uma proposta com jogos cooperativos em tabuleiro. In: VALENCIO, N.; SIENA, M.; MARCHEZINI, V.; GONÇALVES, J. C. (Orgs.). Sociologia dos desastres: construção, interfaces e perspectivas no Brasil. São Carlos: NEPED/UFSCAR, 2009, p. 216-224.

VALENCIO, N. Da morte da Quimera à procura de Pégaso: a importância da interpretação sociológica na análise do fenômeno denominado desastre. In: VALENCIO, N.; SIENA, M.; MARCHEZINI, V.; GONÇALVES, J. C. (Orgs.). Sociologia dos desastres: construção, interfaces e perspectivas no Brasil. São Carlos: NEPED/UFSCAR, 2009, p. 3-18.

O Sistema Nacional de Defesa Civil (Sindec) diante das mudanças climáticas: desafios e limitações da estrutura e dinâmica institucional. In: VALENCIO, N.; SIENA, M.; MARCHEZINI, V.; GONÇALVES, J. C. (Orgs). Sociologia dos desastres: construção, interfaces e perspectivas no Brasil. São Carlos: NEPED/UFSCAR, 2009, p. 19-33. 


\section{Endereço para correspondência Melina Carvalho Trindade}

Rua Tobias da Silva, 248, $1^{\circ}$ andar, Moinhos de Vento, CEP: 90570-020, Porto Alegre-RS, Brasil

Endereço eletrônico: melctrindade@hotmail.com

\section{Monise Gomes Serpa}

Rua Silva Jardins, 1175, Centro, CEP: 97010-491, Santa Maria-RS, Brasil

Endereço eletrônico: monise.serpa@gmail.com

Recebido em: 19/04/2011

Reformulado em: 18/07/2011

Aceito para publicação em: 19/09/2011

Acompanhamento do processo editorial: Rita Maria Manso de Barros

\section{Notas}

* Psicóloga formada pela UNIFRA, especialista em Terapia de Família; e especializanda em Terapia de Casal e em Terapia Cognitiva-Comportamental. Realiza pesquisas na área da psicologia clínica e no âmbito da psicologia dos desastres.

**Professora de Psicologia da UNIFRA, mestre em Psicologia pela UFRGS e doutoranda em Educação pela UFRGS. Orienta trabalhos realizados na Atenção Básica em Saúde, escolas e instituições voltadas para crianças e adolescentes a partir da perspectiva da Psicologia Comunitária e Saúde Coletiva. Realiza pesquisas sobre prostituição, violência sexual (abuso e exploração sexual) na perspectiva dos estudos culturais e pós-estruturalista de gênero.

${ }^{1}$ Situações de emergência são aquelas que colocam as pessoas em alerta de perigo, mas quando esse fato ainda pode ser subvertido e enfrentado pela comunidade. Por outro lado, as situações de desastres ocasionam danos humanos, materiais e ambientais tão intensos que geram impactos e consequências na mesma proporção. Nesse caso, a comunidade como um todo precisa de ajuda externa para restabelecer a sua normalidade (LOPES et al, 2009).

${ }^{2}$ Tsunami é uma palavra japonesa que significa uma onda, ou uma série de ondas que podem ocorrer nos oceanos, baías, lagos, rios ou reservatórios. Essas ondas podem ser originadas a partir de atividades sísmicas ou de vulcanismo, por deslizamento de terra, pelo impacto de um meteorito, ou por um fenômeno meteorológico (BRYANT, 2008).

${ }^{3}$ Os desastres podem ser divididos em três etapas: a do pré-impacto, fase que antecede o evento, onde há alerta ou ameaça de desastre; a do impacto, que é o momento em que as pessoas são atingidas pelos desastres, e a fase do pósimpacto, que se inicia após o desastre ocorrido (OCAMPO, 2006).

${ }^{4}$ A condição de desalojado ocorre quando há parentes ou amigos que estão dispostos a compartilhar suas casas com as pessoas que tiveram que sair de suas moradias. Já a condição de desabrigado, é quando não há parentes ou amigos para socorrer, e então, as pessoas têm que se estabelecer temporariamente em abrigos públicos. Em ambos os casos, as referências de vizinhança são dissolvidas (SIENA e VALENCIO, 2006).

${ }^{5}$ Perspectiva psiquiatrizante diz respeito à doença mental e a um modelo de intervenção difundido pela prática e pelo saber médico clínico, que foi discutido na Reforma Psiquiátrica. Até então, eram realizadas intervenções puramente curativas, baseando-se apenas no diagnóstico, sem considerar as causas e o meio social, e sem se preocupar com a promoção da saúde (FILHO, 2001). 